sensory loss might have made her particularly vulnerable to the seizure threshold lowering effects of clomipramine. To our knowledge there has been only one other report that $\mathrm{MH}$ began in two patients shortly after the initiation of an antidepressant (amtriptyline $75 \mathrm{mg}$ and nortriptyline $75 \mathrm{mg}$ ) (Wegel et al, 1989).

Berrios, G. E. (1990) Musical hallucinations. A historical and clinical study. British Journal of Psychiatry, 156, 188-194.

Fenton, G. W. \& MCRAE, D. A. (1989) Musical hallucinations in a deaf elderly woman. British Journal of Psychiatry, 155, 401-403.

Keshavan, M. S., Kahn, E. M., Brar, J. S. (1988) Musical hallucinations following removal of a right frontal meningioma. Journal of Neurology, Neurosurgery \& Psychiatry, 51, 1235-1236.

MCLoughuIN, I. (1990) Musical hallucinations. British Journal of Psychiatry, 156, 452.

Wegel, S. P.. Burke, W. J. \& Holemon, D. (1989) Musical hallucinations. The sounds of silence? Journal of the American Geriatric Society, 37, 163-166.

Institute of Psychiatry

H. P. VAllada

Genetics Section

De Crespigny Park

London SE5 8 AF

Departamento de Psiquiatrica

Universidade de Sao Paulo, Brazil

V. GENTIL

\section{Crossover reaction between haloperidol and amoxapine for NMS}

SIR: Neuroleptic malignant syndrome (NMS) is a potentially fatal complication of neuroleptic treatment. This syndrome has also been reported in association with antidepressants (Baca \& Martinelli, 1990; Halman \& Goldbloom, 1990). We report a crossover reaction between a neuroleptic (haloperidol) and an antidepressant (amoxapine), which has not previously been reported.

Case report. The patient was a 68-year-old woman (body weight $41 \mathrm{~kg}$ ) suffering from major depression with psychotic features. Nine days before admission, amitriptyline $(30 \mathrm{mg} / \mathrm{day})$ was introduced. On admission, the prescription was switched to haloperidol $1 \mathrm{mg}$ and mianserin $10 \mathrm{mg}$, daily. Haloperidol was gradually increased, and from the 12 th day of admission the daily dose was fixed to $10 \mathrm{mg}$. On the 17th day, the following clinical symptoms and laboratory findings were observed: stupor, lead-pipe muscle rigidity, a fever of $38.9^{\circ} \mathrm{C}$ axillary, autonomic disturbances (hypertension, tachycardia, profuse diaphoresis, and dysuria), an elevated serum creatine phosphokinase (CPK) level (640 IU/l: normal value, 30-170 IU/l), leucocytosis $\left(12100 / \mathrm{mm}^{3}\right)$, and a low serum iron level $(14 \mu \mathrm{g} / \mathrm{dl}$ : normal value, $50-170 \mu \mathrm{g} / \mathrm{dl}$ ). A diagnosis of NMS was made, and all medication was discontinued. All symptoms of NMS disappeared by dantrolene and subsequent levodopa treat- ment. During the next 14 months, several antidepressants, such as mianserin (10-20 mg/day, 23 weeks), maprotiline (10-30 mg/day, 4 weeks), and clomipramine $(10-50 \mathrm{mg} /$ day, 4 weeks) were prescribed with no significant improvement in depression. Finally, amoxapine $(25 \mathrm{mg} /$ day) was introduced. On the 21 st day, the development of NMS was unequivocal. The following clinical symptoms and laboratory findings were observed: stupor, lead-pipe muscle rigidity, a fever of $39.0^{\circ} \mathrm{C}$, autonomic disturbances, an elevated serum CPK level (1090 IU/l), and a low serum iron level $(10 \mu \mathrm{g} / \mathrm{dl})$. Amoxapine was withdrawn, and all symptoms of NMS disappeared with levodopa treatment. Blood analysis including serum iron level was normal except in the NMS episodes.

Some investigators have postulated facilitative roles of increased noradrenergic (Baca \& Martinelli, 1990) or serotonergic (Halman \& Goldbloom, 1990) activity in the pathogenesis of NMS. However, in the present patient, who was apparently very susceptible to NMS, of the antidepressants prescribed, only amoxapine, which has a significant dopaminergic blockade property (Cohen et al, 1982), caused NMS, while the remaining antidepressants which all potentiate noradrenergic and/or serotonergic activities did not. Thus, the present report suggests that dopaminergic blockade sufficiently explains the pathogenesis of NMS (Otani et al, 1991), and that facilitative roles of noradrenalin and serotonin are minute. Although the cause(s) of dramatic fall in serum iron level in NMS remains obscure, this may further facilitate hypodopaminergic states as suggested by Rosebush \& Stewart (1989), since iron deficiency diminishes central dopaminergic activity.

BACA, L. \& MARTINELLI, L. (1990) Neuroleptic malignant syndrome: a unique association with a tricyclic antidepressant. Neurology: 40, 1797-1798.

Cohen, B. M., Harkis, P. Q., Altesman, R. I., el al (1982) Amoxapine: neuroleptic as well as antidepressant? American Journal of Psychiatry, 139, 1165-1167.

Halman, M. \& Goldbloom, D. S. (1990) Fluoxetine and neuroleptic malignant syndrome. Biological Psychiatry, 28, 518-521.

Otani, K., Horiuch, M., Kondo, T., et al (1991) Is the predisposition to neuroleptic malignant syndrome genetically transmitted? British Journal of Psychiatry, 158, 850-853.

RosebUSH, P. \& STEWART, T. (1989) A prospective analysis of 24 episodes of neuroleptic malignant syndrome. American Journal of Psychiatry, 146, 717-725.

\section{KOICHI OTANI KazUO MiHARA MOTOHIRO OKADA Sunao Kaneko} Department of Neuropsychiatry Hirosaki University Hospital Hirosaki 036, Japan 